\title{
An ecological rationale for sustainable forest management concepts at Riverside Forest Products, southcentral British Columbia
}

\author{
by Robert G. D'Eon ${ }^{1}$, Daryll Hebert ${ }^{2}$ and Stephen L. Viszlai ${ }^{3}$
}

Riverside Forest Products (Kelowna, British Columbia) has embraced a sustainable forest management approach for the management of one its forest tenures-Tree Farm License 49. This document discusses the rationale behind many of the concepts within this approach in the context of current ecological theory. We focus specifically on the following concepts: (1) forest retention, (2) ecosystem representation, (3) ecological contributions from unharvested forests, (4) zoning and the TRIAD approach, (5) stand-level habitat elements and landscape-level features, and (6) ecological indicators. This document provides an example of the application of current ecological theory within a commercial forestry operation in Canada and is thus broadly applicable to foresters, forest managers, and researchers in most jurisdictions.

Key words: British Columbia, criteria and indicators, ecological representation, forest retention, sustainable forest management, Riverside Forest Products, TRIAD

Riverside Forest Products (Kelowna, Colombie-Britannique) a décidé d'appliquer une approche d'aménagement forestier durable dans le cadre de l'aménagement de l'une de ces concessions, la concession d'aménagement forestier 49. Cet article présente le raisonnement à la base de plusieurs des concepts retrouvés au sein de cette approche en vertu de la théorie écologique actuelle. Nous nous concentrons spécifiquement sur les concepts suivants: (1) la rétention forestière, (2) la représentation écosystémique, (3) les contributions écologiques des forêts non récoltées, (4) le zonage et l'approche TRIAD, (5) les éléments de l'habitat au niveau du peuplement ainsi que les caractéristiques au niveau du paysage et (6) les indicateurs écologiques. Cet article comprend un exemple de l'application de la théorie écologique actuelle au sein d'une opération forestière commerciale au Canada et qui est en conséquence utilisable de façon générale par les forestiers, les aménagistes forestiers et les chercheurs de la plupart des juridictions.

Mots-clés: Colombie-Britannique, critères et indicateurs, représentation écologique, rétention forestière, aménagement forestier durable, Riverside Forest Products, TRIAD

\section{Introduction}

Sustainable forest management (SFM) has become a cornerstone of forest management around the world. On one of their licencesTree Farm Licence 49 (TFL 49)-Riverside Forest Products (Kelowna, British Columbia) has delivered an ecological stewardship plan (Riverside 2003) that outlines a 25-year framework for implementation of a SFM

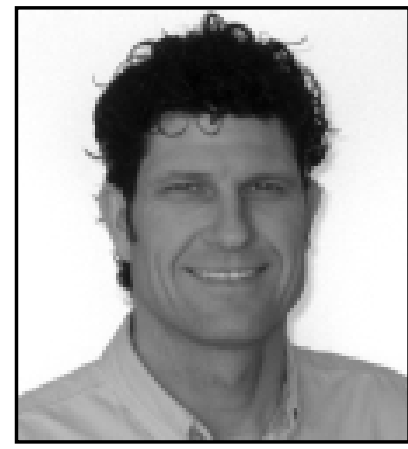

Robert G. D'Eon approach. TFL 49 is a 145000 -ha forest tenure with a current annual allowable cut of $380000 \mathrm{~m}^{3}$, located along the west shore of Okanagan Lake in the south-central interior of British Columbia $\left(51^{\circ} 20^{\prime} \mathrm{N}, 119^{\circ} 55^{\prime} \mathrm{W}\right)$ primarily within the Montane Spruce, Interior Douglas-fir, and Engelmann Spruce Sub - alpine Fir biogeoclimatic zones (described by Pojar et al. 1987).

Briefly, the SFM approach is based on the goal of sustainable development, which in this case involves indefinitely maintaining forest values (as currently defined) for future generations

\footnotetext{
${ }^{1} 414$ Observatory Street, Nelson, British Columbia V1L 4Y6 E-mail: rdeon@interchange.ubc.ca (corresponding author).

${ }^{2}$ Encompass Strategic Resources, RR2, 599 Highway 21, South Creston, British Columbia V0B 1G2.

${ }^{3}$ Riverside Forest Products, 844 Otter Lake X Roads, Armstrong, British Columbia V0E 1B0.
}

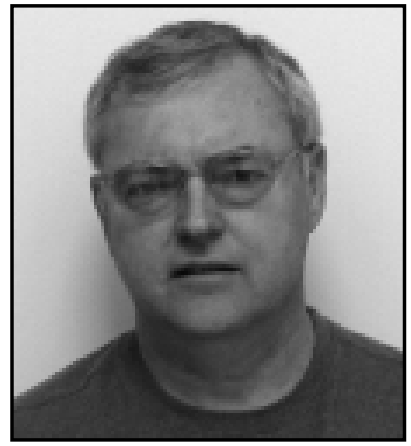

Daryll Hebert

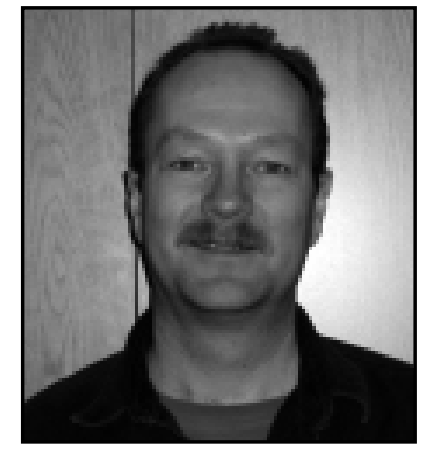

Stephen L. Viszlai by achieving an optimal balance of socially, economically, and ecologically sustainable values (Bruntland 1997). A critical component of the approach is the use of strategic tradeoffs in achieving this optimal balance. This document provides background and rationale for key ecological concepts adopted by Riverside, and specifically focuses on the following concepts as they relate to ecological sustainability and the conservation of biodiversity, a primary goal of SFM (Criterion 1 of CCFM 1997): (1) forest retention, (2) ecosystem representation, (3) ecological contributions from unharvested forests, (4) zoning and the TRIAD approach, (5) standlevel habitat elements and landscape-level features, and (6) ecological indicators. It exemplifies an application of current ecological theory within an industrial forestry context and is thus broadly applicable to foresters, forest managers, and researchers in most jurisdictions. 


\section{Forest Retention - How Much Do We Retain?}

Excluding a portion of forests from harvesting or other human disturbance has been a long-recognized part of biodiversity conservation strategies around the world (Hunter 1990, United Nations 1992). In fact, establishing an ecologically representative system of reserves is the goal of protected area strategies in many jurisdictions (e.g., Province of British Columbia 1993). Entire ecosystem retention is the foundation of a coarsefilter approach for conserving the countless poorly understood or completely unknown organisms in British Columbian forests (e.g., BC Ministry of Environment 1995). However, setting aside the majority or large portions of the available forested landbase is impossible in most cases due to the socio-economic impacts (e.g., reduced harvest levels) of doing so-as a result, some smaller amount of forest is typically targeted for retention or reserve.

Recommended amounts of forest retention vary somewhat arbitrarily from approximately $10 \%$, in cases where largely administrative constraints are imposed (Bruntland 1987), to levels exceeding 50\% where conservation priorities dominate (e.g., Soulé and Sanjayan 1998). Fortunately, up to 50\% or more of the forested area within forest tenures in British Columbia is not available for harvest because of inoperable (e.g., steep or fragile terrain) and constrained (e.g., wildlife reserves, riparian management, visual corridors) areas - thereby meeting or exceeding most recommendations. However, because non-harvested areas of this nature may or may not contain ecologically representative ecosystems, ecological representation rather than sheer amount of area becomes the central question.

In an analysis of non-harvestable areas (also referred to as the non-harvestable land base or NHLB) within TFL 49, Serrouya et al. (2002) determined that $10.2 \%$ of the tenure was fully constrained (i.e., unharvestable for legal or operational reasons; Fig. 1) and therefore outside the timber harvesting land base (THLB $=$ unconstrained area available for harvest). While on the low end of the spectrum, this is consistent with calls for $\geq 10 \%$ forest retention. On this basis alone therefore, TFL 49 contains significant amounts of non-harvestable areas prior to any other planning or management efforts. However, as stated, because the NHLB may or may not represent the full spectrum of ecosystem diversity in an area, the question in this case is not one of amount, but rather one of ecological representation.

\section{Evaluating Ecosystem Representation within the Non-Harvestable Land Base}

Bunnell et al. (2003; see also Kremsater et al. [2003] who summarize Bunnell et al. [2003]) advocated that ecological representation in the NHLB is the critical question concerning retention strategies within British Columbian forests. Ecosystem representation via the establishment of representative reserves and protected areas has been a conservation centrepiece around the world for decades (Arcese and Sinclair 1997) and a critical component of coarse-filter ecosystem management approaches (e.g., Haufler et al. 1996). Reserves and protected area strategies represent a coarse-filter approach to conservation and biodiversity management where areas are set aside from development with the objective of providing habitat for the myriad species existing within their boundaries. A key target, therefore, of most protected area strategies is to provide not only sufficient amounts of area, but also representative habitat from the spec- trum of ecological diversity within a given area (e.g., Province of British Columbia 1993). In much the same way, the broad goal of a coarse-filter approach to biodiversity conservation within non-harvestable areas in a managed forest such as TFL 49 is to evaluate the degree to which the NHLB will provide habitat that is representative of the ecological diversity within the management unit.

A key requirement of this approach is the identification of distinct and meaningful ecological strata, from which ecological representation can be evaluated. In British Columbia, the Biogeoclimatic (BEC) system (Pojar et al. 1987) is a system of ecological land classification that provides a useful basis. The system is hierarchical with the broadest vegetation-based stratum referred to as the "zone." Zones are very broad classifications (provincial resolution; often hundreds of thousands of hectares) based on a dominant climax tree community (e.g., Interior Douglas-fir $=$ IDF). Zones are dissected into subzones and variants based on relative precipitation, temperature and geographic localization (e.g., Interior Douglas-fir moist warm, variant $1=$ IDFmw1). The finest resolution within this system is the "site series" which places all sites in a subzone variant within an edaphic grid (moisture versus nutrient), where each variant could therefore have numerous site series (e.g., Interior Douglas-fir moist warm, variant 1 , site series $04=$ IDFmw1-04). At this resolution, site series polygons are typically between 1 and 100 ha.

Site series or site series grouping has been used successfully in British Columbia and has provided an ecological classification with a resolution appropriate for wildlife community associations in the context of ecological representation analyses (Huggard 2000, Wells et al. 2003). Using similar methods, Herbers and Serrouya (2001) identified 23 site series groups within TFL 49 and provided the required framework for an ecological representation analysis of TFL 49 (Serrouya et al. [2002]; the results of this analysis are discussed in the next section).

\section{Ecological Contributions from Unharvested Forests}

Unharvested forests within management units such as TFL 49 typically occur within a variety of land classification zones with a range of retention objectives. Serrouya et al. (2002) reported that $10.2 \%$ of TFL 49 was within the NHLB (NHLB $=90 \%$ to $100 \%$ constrained) and another $43.4 \%$ that was within the partially constrained (PCLB $=40 \%$ to $90 \%$ constrained) and the lightly constrained (LCLB $=10 \%$ to $40 \%$ constrained) land bases (Fig. 1). These figures are consistent with the contention that amounts of unmanaged forest in British Columbia largely exceed most area-based recommendations. However, as discussed, the critical question is not one of sheer amount, but rather: "do the unharvested areas account for the entire spectrum of ecological diversity found in TFL 49?"

Serrouya et al. (2002) calculated the amount of area within each land base category for each site series grouping in TFL 49 (Table 1). By calculating the total contribution from all land base types (see Table 1 for the derivation of this calculation), all site series groupings are demonstrated to have greater than $10 \%$ of their area within constrained land bases and therefore meet a $10 \%$ retention objective. Further, all but three groupings met a $20 \%$ retention target- the exceptions are groupings 16,22 , and 23 , with $19 \%, 18 \%$, and $10 \%$, respectively, within constrained land bases. Therefore, if a $10 \%$ retention target 


$$
\begin{aligned}
& \text { 1. FCLB }-10.2 \%-\text { NHLB }-10.2 \% \\
& \text { 2. PCLB }-14.4 \%-7 \\
& \text { 3. } \mathrm{LCLB}-29.0 \% \\
& \text { 4. } \mathrm{UNLB}-46.4 \%
\end{aligned} \quad-\text { THLB }-89.8 \%
$$

Fig. 1. Area distribution within regulatory land strata within the non-harvested land base (NHLB) and the timber harvesting land base (THLB) in TFL 49; FCLB = fully constrained landbase, PCLB $=$ partially constrained land base, $\mathrm{LCLB}=$ lightly constrained land base, UNLB = unconstrained land base. Values represent proportional amounts within each stratum by area from Serrouya et al. (2002).

is desirable, it could be met entirely within the constrained land bases. If however, a $20 \%$ retention target is desirable, additional retention must be secured within the unconstrained land base within site series groupings 16, 22, and 23.

Serrouya and Herbers (2002) also addressed the issue of habitat structure representation within the constrained land bases of TFL 49. The notion under consideration was that although ecosystem representation (e.g., by site series grouping by area) may occur within constrained areas, if structural habitat elements - arguably the crux of the representation issueare not present in the constrained land base for any reason, it would undermine the ecological representation argument.

Based on a rich literature of associations between habitat attributes and specific organisms (e.g., Thomas 1979) and recent applications within British Columbia (Bunnell et al. 2003, Huggard 2001), Serrouya and Herbers (2002) focussed on measurements of three habitat attributes: (1) dead and dying wood, (2) vegetation layers, and (3) vertical and horizontal stand structure. They measured stand structural components within each of these categories among site series groups within the constrained and unconstrained land bases. They found no consistent differences related to habitat structural attributes. This conclusion provides reassurance that site series groups within unharvested areas can provide habitat similar to site series groups in the harvestable land base and provides support for a coarse filter representation approach to biodiversity conservation in TFL 49.

\section{The TRIAD Forest Management Approach: Is It Applicable To TFL 49?}

Zoning has been repeatedly advocated as an approach to forest management planning in efforts to more effectively and efficiently meet multiple resource objectives at broad scales (e.g., Binkley 1997, Messier and Kneeshaw 1999, Beese et al. 2003). This approach is often referred to as the TRIAD forest management approach (Seymour and Hunter 1999). The essential property of this approach is the identification of distinct zones with associated sets of differing objectives and procedures - usually based on three zones: Production (Intensive) Zone, Extensive (Multiple Use) Zone, and Ecological (Reserves) Zone. The objective of the TRIAD approach is to produce a landscape design and management system that will provide for all societal demands using intelligent decision-making and tradeoff analyses. One of the central concepts to this approach is the notion that representative reserves can be set aside while attempting to maintain timber yields through a compensatory increase in production silviculture in other zones.

Within TFL 49, a wide spectrum of ecological diversity occurs across five biogeoclimatic (BEC) zones (Table 2). This wide spectrum provides a basis for a TRIAD approach within TFL 49 by providing a variety of zoning options that could be designed to meet different objectives. For example, the Montane Spruce (MS) zone of the British Columbia interior is generally regarded as a smaller contributor to biodiversity than other BEC zones such as Interior Douglas-fir (IDF) since it supports a smaller number of vertebrate species (Fig. 2). Recent work in TFL 49 demonstrated lower bird species richness with increasing amounts of lodgepole pine-the dominant tree species in the MS zone (Herbers et al. 2003). As well, no rare or endangered vertebrate species are unique to the MS zone within TFL 49, versus two listed species unique to the IDF zone, three within the Ponderosa pine zone, and one unique species within the Engelmann spruce sub-alpine zone (Bunnell et al. 1999a). Within TFL 49, the MS zone extends across 55053 ha ( $\sim 40 \%$ of TFL 49 ), and therefore represents large opportunities for more intensive management to compensate for other management focuses, such as biodiversity, in other zonesconsistent with a TRIAD approach.

\section{Habitat Elements and Landscape Features: What Do We Manage? Habitat elements}

Most forest-dwelling vertebrate species can be directly associated with one or more forest stand habitat element (Thomas 1979; Table 2). A habitat element in this context is a structural component of a stand, usually independent of stand age and surrounding habitat. Almost all species considered "at risk" in British Columbia are directly related to one or more structural habitat element (Bunnell et al. 1999a). Bunnell et al. (2003) recommend monitoring six habitat elements for evaluating success in sustaining biodiversity within forests: (1) large live trees, (2) snags (standing dead trees), (3) downed wood (coarse woody debris), (4) canopy cover and composition, (5) shrubs, (6) herbaceous ground cover. Because of a demonstrated and direct link between organisms and measurable stand habitat elements, managing and monitoring habitat elements should be a major component in any biodiversity management strategy.

Generally, large-scale commercial timber extraction reduces the abundance of important structural elements within forestsmost notably large live trees, snags, and downed wood. These structural elements can only be created by either growing (recruiting) large trees and leaving them behind to die and eventually fall to the ground, or, by retaining existing structure of this kind. Either option presents a conflict to forest managers in that large live trees are generally the target of timber extraction operations. Indeed, data from European forests reveals that intensive forestry (i.e., forests managed to maximize fibre productivity) can virtually eliminate snags and down wood after several rotations (Berg et al. 1994).

Arguably the most effective means of retaining and recruiting stand habitat elements in managed forests is by variable retention - a strategy advocated by many (Clayoquot Sound Scientific 


\begin{tabular}{|c|c|c|c|c|c|c|}
\hline \multirow[b]{2}{*}{$\begin{array}{l}\text { Site series } \\
\text { group }^{c}\end{array}$} & \multicolumn{6}{|c|}{ Proportion (\%) within TFL 49 by site series group $^{b}$} \\
\hline & $\begin{array}{l}\text { Total area in } \\
\text { TFL } 49 \text { (ha) }\end{array}$ & FCLB & PCLB & LCLB & UNLB & $\begin{array}{l}\text { Total proportion in } \\
\text { constrained land base }\end{array}$ \\
\hline 1 & 2745 & 35.1 & 39.5 & 24.5 & 0.9 & 65 \\
\hline 2 & 241 & 29.6 & 3.5 & 54.3 & 12.5 & 44 \\
\hline 3 & 8931 & 20.6 & 32.2 & 41.3 & 5.9 & 51 \\
\hline 4 & 809 & 35.6 & 23.6 & 40.0 & 0.7 & 59 \\
\hline 5 & 826 & 13.5 & 50.0 & 36.4 & 0.0 & 54 \\
\hline 6 & 369 & 30.8 & 13.5 & 48.9 & 6.8 & 50 \\
\hline 7 & 41687 & 13.3 & 14.6 & 44.8 & 27.3 & 33 \\
\hline 8 & 807 & 7.8 & 59.5 & 28.6 & 4.2 & 53 \\
\hline 9 & 4259 & 12.0 & 7.6 & 51.3 & 29.0 & 29 \\
\hline 10 & 54 & 22.5 & 13.1 & 22.1 & 42.3 & 35 \\
\hline 11 & 744 & 37.6 & 6.2 & 38.9 & 17.3 & 49 \\
\hline 12 & 152 & 33.4 & 14.3 & 44.8 & 7.5 & 52 \\
\hline 13 & 48 & 93.1 & 0.0 & 6.9 & 0.0 & 90 \\
\hline 14 & 22 & 83.5 & 0.6 & 12.0 & 3.9 & 83 \\
\hline 15 & 284 & 61.1 & 2.7 & 26.2 & 10.0 & 66 \\
\hline 16 & 44316 & 5.2 & 12.2 & 24.2 & 58.4 & 19 \\
\hline 17 & 2788 & 12.6 & 8.7 & 24.8 & 53.9 & 24 \\
\hline 18 & 486 & 34.8 & 4.3 & 17.7 & 43.1 & 40 \\
\hline 19 & 55 & 34.6 & 1.6 & 3.0 & 60.8 & 35 \\
\hline 20 & 155 & 88.7 & 3.5 & 4.8 & 3.0 & 88 \\
\hline 21 & 33 & 91.0 & 0.0 & 0.0 & 9.0 & 86 \\
\hline 22 & 2013 & 13.2 & 6.4 & 5.8 & 74.6 & 18 \\
\hline 23 & 25992 & 2.7 & 9.3 & 5.7 & 82.3 & 10 \\
\hline
\end{tabular}

a Data provided by J. Herbers and originally presented as Fig. 2 in Serrouya et al. (2002).

${ }^{b}$ Ecological stratification by site series groupings from Herbers and Serrouya (2001).

${ }^{\mathrm{c} F C L B}=$ fully constrained, PCLB $=$ partially constrained, LCLB $=$ lightly constrained, UNLB $=$ unconstrained.

${ }^{\mathrm{d}}$ Total contribution by site series grouping derived from midpoint land base definitions in Serrouya et al. (2002) as follows: FCLB assumed to contribute 95\% of area; $\mathrm{PCLB}=65 \%$ of area; $\mathrm{LCLB}=25 \%$ of area; $\mathrm{UNLB}=0 \%$ contribution. e.g., site series group $17:(12.6$ ha $\times 95 \%)+(8.7$ ha $\times 65 \%)+(24.8 \times 25 \%)=23.8 \%$.

Table 2. Proportion of vertebrate species by biogeoclimatic (BEC) zone restricted to or favouring habitat elements and types within TFL 49 (modified from Bunnell et al. 1999a)

\begin{tabular}{lccccccc}
\hline & \multicolumn{5}{c}{ Proportion of total species (by zone) restricted to or favouring } \\
\cline { 2 - 7 } BEC zone $^{\text {a }}$ & Cavities & Downed wood & Shrubs & Hardwoods & Riparian & Early seral & Late seral \\
\hline PP & 30 & 13 & 19 & 31 & 46 & 23 & 22 \\
IDF & 28 & 14 & 18 & 31 & 46 & 30 \\
MS & 28 & 16 & 14 & 30 & 47 & 20 & 22 \\
ICH & 26 & 15 & 21 & 29 & 49 & 22 \\
ESSF & 25 & 18 & 14 & 19 & 45 & 21 \\
\hline
\end{tabular}

${ }^{\mathrm{a}} \mathrm{PP}=$ Ponderosa pine, IDF = Interior Douglas-fir, Montane spruce, Interior Cedar Hemlock, Engelmann Spruce Sub-alpine fir zones (Meidinger and Pojar 1991).

Panel 1995, Franklin et al. 1997, Beese et al. 2003). While not entirely new-classic silviculture systems such as shelterwood, seed tree, and even clearcutting typically involve some form of retention - variable retention is a management strategy where portions of available stands are retained to meet nontimber objectives such as biodiversity Retention of this nature has two parameters: amount (i.e., proportion of the stand area or volume retained) and distribution (e.g., dispersed or aggregated). Since all organisms are uniquely adapted to a wide array of specific habitat conditions, it follows that there is no single retention prescription that meets all the needs of all organisms. It is therefore widely advocated that the best retention strategy incorporates a variety of patterns across the landscape and avoids doing the same thing everywhere (Bunnell et al. 1999b). However, some generalities can be offered such as: retaining large live trees $(\geq 50 \mathrm{~cm}$ diameter) to provide a future source of snag and downed wood habitat; retaining deciduous trees since they are often preferred by many species; retaining 2 snags/ha will provide adequate snag habitat while additional snags in excess of 4 snags/ha adds little value; aggregated patches (groups of trees) are generally considered of higher habitat value than individually dispersed leave trees because patches tend to accommodate a wider community of organisms than individual trees; riparian areas generally contribute disproportionately to biodiversity objectives and are therefore a very important component of any retention strategy (Bunnell et al 1999b and 2003, and references therein).

\section{Landscape features}

"Landscape features" are elements of forests that involve the spatial configuration of habitat - typically at the resolution of habitat patches. While a rich theoretical literature pertaining to the study of spatial configuration of ecological elements exists (e.g., Forman 1999, Gergel and Turner 2002), it is mostly unclear exactly how species respond to spatial configuration of habitat from empirical work. As a result, very few tangible recommendations are available to forest managers (D'Eon 2002, Boutin and Hebert 2002). The most obvious reason for this is simply the lack of consistent empirical evidence either supporting or rejecting ideas concerning organism response to spatial 


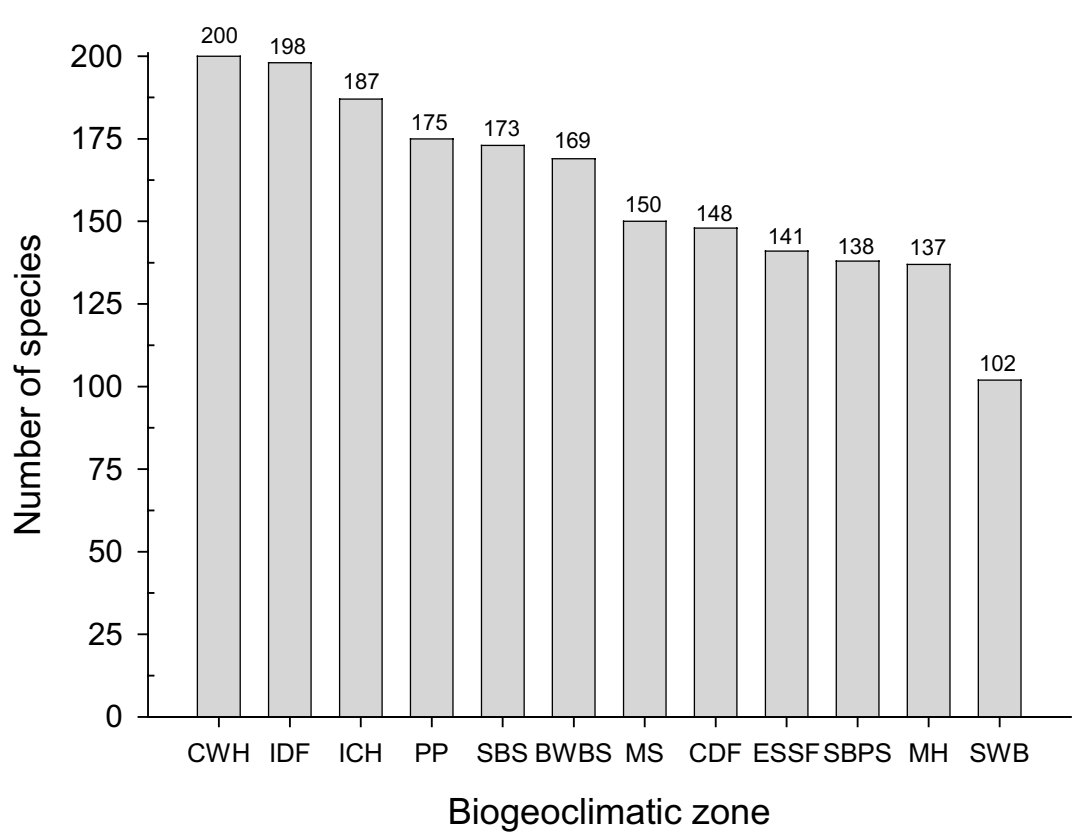

Fig. 2. Numbers of forest-dwelling vertebrates breeding in the 12 forested biogeoclimatic zones of British Columbia (from data presented in Bunnell et al. 1999b). Zones from Meidinger and Pojar (1991): CWH = coastal western hemlock, IDF $=$ interior Douglas-fir, ICH $=$ interior cedar hemlock, $\mathrm{PP}=$ Ponderosa pine, $\mathrm{SBS}=$ sub-boreal spruce, $\mathrm{BWBS}=$ black and white boreal spruce, $\mathrm{MS}=$ montane $\mathrm{spruce}, \mathrm{CDF}=\mathrm{coastal}$ Douglas-fir, ESSF = Engelmann spruce sub-alpine fir, SBPS = sub-boreal pine spruce, $\mathrm{MH}=$ mountain hemlock, $\mathrm{SWB}=$ spruce, willow, birch

configuration of habitat elements. In a review of literature on forest fragmentation (arguably one of the most central landscape ecology issues relevant to forest management), Debinski and Holt (2000) stated that the evidence for or against fragmentation effects was inconclusive at best. As well, while literally hundreds of landscape metrics (the most common form of landscape pattern measurement) exist (Gufstafson 1998), measurements of landscape pattern and their applications are underdeveloped and poorly understood (D'Eon and Glenn 2000). Finally, recent work suggests that the amount of habitat largely outweighs any effects related to spatial configuration of habitat elements, suggesting that managers should currently be more concerned with habitat amount than spatial configuration (Boutin and Hebert 2002, Fahrig 2002, McGarigal and Cushman 2002). Clearly, more empirical work is required before clear and tangible landscape pattern recommendations can be delivered to forest managers (D'Eon 2002).

In the face of this lack of clarity, Bunnell et al. (2003) advocated monitoring — as a low priority — three landscape elements that are generally believed to be important to the maintenance of biodiversity (e.g., see Hunter 1990): (1) age and patch size distribution, (2) edge density or related index, and (3) road density. Many have recommended the maintenance of a range of age and patch sizes in any forested landscape (e.g., Hunter 1990, BC Ministry of Environment 1995). The rationale for this strategy is that by maintaining landscape heterogeneity similar to a natural forest structure, the wide range of species adapted to such a forest structure will more likely be maintained than doing otherwise. Empirical evidence on the age and patch size structure resulting from natural disturbance regimes provides a useful starting point (e.g., Bunnell 1995, Delong and Tanner 1996, Chissel et al. 1999, Bergeron et al. 2002).

\section{Habitat elements versus landscape features}

There are clear, tangible, and demonstrated links between organisms and dependencies on stand structural elements. In comparison, relatively little is known or unequivocal about organism response to landscape spatial pattern. As well, recent evidence suggests that habitat amount should be the sole priority of forest managers until very small amounts of habitat remain (20-30\%, Boutin and Hebert 2002), at which point spatial configuration should also be considered. An important consideration, however, is that spatial legacies are persistent and current harvest patterns can persist on the landscape for several rotations (Nelson and Wells 2000). Current patterns therefore should be considered and managed so that future options are not precluded.

\section{Indicator Species: What Should We Monitor?}

One of the most often-cited goals or criteria of sustainable forest management is the conservation of biological diversity (CCFM 1997, Kimmins 1999, Kneeshaw et al. 2000). Biological diversity, or biodiversity, is a widely used term with myriad definitions (Delong 1996). For the purposes of this document, we refer to biodiversity as including the relative implications of the number, distribution, and abundance of species in an area-in this case TFL 49. Therefore, a direct measure of biodiversity would involve some measure of every species in TFL 49. Few would argue that measuring all species on a forest management scale is an impossible task given limited resources and logistical constraints. As a result, most advocate an indicator species approach (see Landres et al. 1988 and Simberloff 1998 for reviews).

An indicator species approach is one where one or more select species are monitored or managed under the assumption that 
information about them can be used to infer information about other species and/or other environmental properties. Several kinds of indicator species have emerged in the literature, such as, but not limited to: (1) Umbrella species: species whose requirements for persistence are believed to encapsulate those of an array of additional species, (e.g., Northern spotted owl, Strix occidentalis caurina), (2) Flagship species: a symbolic charismatic species used to entice public support by representing a conservation cause or campaign (e.g., Florida panther, Felis concolor coryi), (3) Keystone species: species believed to have a disproportionate influence on its environment and other species (e.g., beaver, Castor canadensis), (4) Focal species: species whose requirements for persistence define the attributes that must be present if that landscape is to meet the requirements of the species (Lambeck 1997).

While intuitively appealing, and agreed upon conceptually by most, the indicator species approach is extremely problematic in practice and rife with debate, confused definitions and conflicting recommendations. The difficulties, problems, and challenges associated with the indicator species approach have been widely cited (e.g., Landres et al. 1988, Caro and O’Doherty 1998, McLaren et al. 1998, Simberloff 1998, Lindenmayer et al. 2000, Hannon and McCallum 2003). Problems include, but are not limited to: the absence of empirical support for the approach, a lack of required natural history information, lack of causation between change in indicator with change in practice, lack of measurable outcomes, scale differences between species and management, a lack of assumed responsibility among agencies, population fluctuations are often unrelated to management, selection of indicator is often based on socio-economic reasons rather than ecological, inadequate numbers for statistical comparisons, migratory species affected by conditions on winter range and migration routes, prohibitive costs, a circularity problem where indicator species are both managed and then used as indicator.

The biggest challenge currently to the indicator approach, even if well-structured and empirically defined, is a lack of solid empirical links between one or a group of species and the management concern of interest (Simberloff 1998, Lindenmayer et al. 2000, Hannon and McCallum 2003). Indeed, recent empirical work demonstrated that umbrella species were no more effective than randomly selected species (Fleishman et al. 2001). Most importantly, many examples exist, hypothetical and real (references previously cited), of cases where a change in some measure of indicator species may or may not have reflected a change in management practices and therefore makes the current utility of the approach, at best questionable, at worst a wasteful diversion of limited management resources. Without exception, there is a loud call for empirical research to establish links between indicator species and management concerns to validate the approach (references previously cited). Without adequate research it is difficult, if not impossible, to judge the efficacy of an indicator species as an index for other environmental variables (Landres et al. 1988). Empirical evidence of this nature is currently not available (but see Watson et al. 2001).

At this time, therefore, we submit it is virtually impossible to provide a low-risk (i.e., low risk of failure), rigorously defendable, unequivocally agreed upon, and easily feasible list of indicator species to meet the management goal of monitoring biodiversity in an area such as TFL 49. Nonetheless, since forests continue to be harvested, a defeatist retreat does not serve the concern. Rather, we suggest the situation is best served by forwarding a list of indicator species, perhaps on a pilot-study basis, and in the spirit of adaptive management (Walters 1986) rigorously and empirically evaluated through time and adjusted as appropriate. By doing so we accept that any list of this nature will involve a degree of uncertainty and risk.

McLaren et al. (1998) and Bunnell et al. (2003; see also Kremsater et al. [2003] who summarize Bunnell et al. [2003]) provide example applications of the indicator species approach in Canada. McLaren et al. (1998) suggested a list of 40 and 48 vertebrate species for monitoring within the boreal and Great Lakes biomes of Ontario, respectively. They classified indicators by their ability to represent broad forest habitat types (e.g., lowland conifer), and further classified into three forest age classes (young, pole/small tree, mature/old) and three spatial scales (stand, forest, landscape) within each habitat type. They forwarded this list of indicator species as a means to test the hypothesis that forest management has no effect on species richness and species abundance, or the distribution of species in time and space. As such, no empirical validation was offered by McLaren et al. (1998), and their recommended strategy has yet to be validated. In a review of ecological standards for sustainable forest management, Kneeshaw et al. (2000) questioned the feasibility of establishing monitoring programs for each species listed by McLaren et al. (1998).

Bunnell et al. (2003) recommended a list of focal species (as defined by Lambeck 1997) for monitoring on a coastal British Columbia forest tenure. Selection of indicator species was based on four criteria: (1) must be forest-dwelling, (2) must be sensitive to forest practices, (3) must be practical to monitor, and (4) must provide information useful in guiding forest practices. They also emphatically contended that the focus should not be on individual species, but trends within groups of species within an overall program. To accomplish this therefore, they recommended a generic monitoring program that includes the identified focal species, but is not limited to species on the indicator list. Doing so not only provides a broader perspective, it also reduces the risk of choosing the wrong indicators. The list provided by Bunnell et al. (2003) is a very inclusive list of hundreds of species chosen from seven broad groups of forest-dwelling organisms. While very comprehensive and rigorously derived, Bunnell et al. (2003) themselves admit their list of species is too long to be practical and must be distilled further-thus highlighting the challenges of implementing the indicator species approach.

TFL 49 supports 194 forest-dwelling vertebrates (Bunnell et al. 1999). While the sole use of vertebrates as indicator species has been criticised (Landres et al. 1988), others (e.g., Bunnell 1995) have suggested vertebrates as suitable since their natural histories are relatively well-known and tend to be easier to monitor than other life forms - two important prerequisites of useful indicators. Regardless of potential criticisms, given the current uncertainty surrounding this issue, relying on a suite of vertebrate indicators is likely no better or worse than any other strategy currently in place. We therefore recommend that a list of vertebrate indicator species can feasibly be proposed for TFL 49 , and especially in light of our knowledge of vertebrate habitat preferences for many stand and forest attributes in this area (Table 2). We strongly recommend that any monitoring plan be implemented on an adaptive management basis (Wal- 
ters 1986) and that rigorous pre- and post-treatment empirical validation be included in the approach.

\section{Acknowledgements}

We are grateful to J. Herbers, K. Maxcy, and R. Serrouya for sharing data they collected in TFL 49. We thank two anonymous reviewers. Riverside Forest Products Ltd. funded the publication of this work.

\section{References}

Arcese, P. and A.R.E. Sinclair. 1997. The role of protected areas as ecological baselines. Journal of Wildlife Management 61: 587-602. BC Ministry of Environment. 1995. Forest practices code biodiversity guidebook. British Columbia Ministry of Forests and Ministry of Environment, Lands and Parks, Queen's printer, Victoria, British Columbia. Beese, W.J., B.G. Dunsworth, K. Zielke and B. Bancroft. 2003. Maintaining attributes of old-growth forests in coastal B.C. through variable retention. The Forestry Chronicle 79: 570-578.

Berg, A., B. Ehnstrom, L. Gustaffsson, T. Hallingback, M. Jonsell and J. Weslien. 1994. Threatened plant, animal, and fungus species in Swedish forests: distribution and habitat associations. Conservation Biology 8: 718-731.

Bergeron, Y., A. Leduc, B.D. Harvey and S. Gauthier. 2002. Natural fire regime: a guide for sustainable management of the Canadian boreal forest. Silva Fennica 36: 81-95.

Binkley, C.S. 1997. Preserving nature through intensive plantation forestry: the case for forestland allocation with illustrations from British Columbia. The Forestry Chronicle 73: 553-559.

Boutin, S. and D. Hebert. 2002. Landscape ecology and forest fragmentation: developing and effective partnership. Ecological Applications 12: 390-397.

Bruntland, G.H. 1987. Our common future: world commission on environment and development. Oxford University Press, Oxford, New York.

Bunnell, F.L. 1995. Forest-dwelling vertebrate faunas and natural fire regimes in British Columbia: patterns and implications for conservation. Conservation Biology 9: 636-644.

Bunnell, F.L., D.J. Huggard and K. Lisgo. 1999a. Vertebrates and stand structure in TFL 49. Unpublished report submitted to Riverside Forest Products, Kelowna, British Columbia.

Bunnell, F.L., L.L Kremsater and E. Wind. 1999b. Managing to sustain vertebrate richness in forests of the Pacific Northwest: relationships within stands. Environmental Review 7: 97-146.

Bunnell, F., G. Dunsworth, D. Huggard and L. Kremsater. 2003. Learning to sustain biological diversity on Weyerhaeuser's coastal tenure. Weyerhaeuser Company Ltd., Nanaimo, British Columbia.

Caro, T.M. and G. O'Doherty. 1998. On the use of surrogate species in conservation biology. Conservation Biology 13: 805-814. CCFM. 1997. Criteria and indicators of sustainable forest management in Canada. Canadian Council of Forest Ministers Technical Report, Natural Resources Canada, Ottawa.

Chissel, J.H., F.J. Swanson and P.J. Weisberg. 1999. Landscape management using historical fire regimes: Blue River, Oregon. Ecological Applications 4: 1217-1231.

Clayoquot Sound Scientific Panel. 1995. Sustainable ecosystem management in Clayoquot Sound: planning and practices. Cortex Consultants, Victoria, British Columbia.

Debinski, D.M. and R.D. Holt. 2000. A survey and overview of habitat fragmentation experiments. Conservation Biology 14: 342-355. Delong, D.C. 1996. Defining biodiversity. Wildlife Society Bulletin. 24: 738-749.

Delong, S.C. and D. Tanner. 1996. Managing the pattern of forest harvest: lessons from wildfire. Biodiversity and Conservation 5: 1191-1205.

D'Eon, R.G. 2002. Forest fragmentation and forest management: a plea for empirical data. The Forestry Chronicle 78: 686-689.
D'Eon, R.G. and S.M. Glenn. 2000. Perceptions of landscape patterns: Do the numbers count? The Forestry Chronicle 76: 475-480. Fahrig, L. 2002. Effect of habitat fragmentation on the extinction threshold: a synthesis. Ecological Applications 12: 346-353.

Fleishman, E., R.B Blair and D.D. Murphy. 2001. Empirical validation of a method for umbrella species selection. Ecological Applications 11: 1489-1501.

Forman, R.T. 1997. Land mosaics. The ecology of landscapes and regions. Cambridge University Press, Cambridge.

Franklin, J.F., D.R. Berg, D.A. Thornburgh and J.C. Tappeiner. 1997. Alternative silvicultural approaches to timber harvesting: variable retention harvest systems. In K.A. Kohm and J.F. Franklin, editors. Creating a forestry for the 21st century. pp. 111-139. Island Press, Washington, DC.

Gergel, S.E. and M.G. Turner (eds.). 2002. Learning landscape ecology: a practical guide to concepts and techniques. Springer-Verlag, New York, New York.

Gustafson, E.J. 1998. Quantifying landscape spatial pattern: what is the state of the art? Ecosystems 1: 143-156.

Haufler, J.B., C.A. Mehl and G.J. Roloff. 1996. Using a coarse-filter approach with species assessment for ecosystem management. Wildlife Society Bulletin 24: 200-208.

Hannon, S.J. and C. McCallum. 2003. Using the focal species approach for conserving biodiversity in landscapes managed for forestry. Sustainable Forest Management Network, National Network of Centres of Excellence, University of Alberta, Edmonton.

Herbers, J., K. Maxcy and R. Serrouya. 2003. Non-migratory birds in Riverside's TFL 49 - terrestrial landbase. Unpublished report submitted to Riverside Forest Products, Kelowna, British Columbia.

Herbers, J. and R. Serrouya. 2001. Grouping site series for representation analysis in Riverside TFL 49. Unpublished report submitted to Riverside Forest Products, Kelowna, British Columbia.

Huggard, D. 2000. Ecological representation in the Arrow IFPA nonharvestable landbase. Unpublished report submitted to the Arrow Innovative Forest Practices Agreement, Slocan, British Columbia.

Huggard, D. 2001. Habitat attributes in the Arrow IFPA non-harvestable land base. Unpublished report submitted to the Arrow Innovative Forest Practices Agreement, Slocan, British Columbia, Canada.

Hunter, M.L., Jr. 1990. Wildlife, forests, and forestry: principles of managing forest for biological diversity. Prentice Hall, Englewoods Cliffs, New Jersey.

Kimmins, J.P. 1999. Biodiversity, beauty and the "beast": Are beautiful forests sustainable, are sustainable forests beautiful, and is "small" always ecologically desirable? The Forestry Chronicle 75: 955-960.

Kneeshaw, D.D., A. Leduc, P. Drapeau, S. Gauthier, D. Paré, R. Carigan, R. Doucet, L. Bouthiller and C. Messier. 2000. Development of integrated ecological standards of sustainable forest management at the operational scale. The Forestry Chronicle 76: 481-493.

Kremsater, L., F. Bunnell, D. Huggard and G. Dunsworth. 2003. Indicators to assess biological diversity: Weyerhaeuser's coastal British Columbia forest project. The Forestry Chronicle 79: 590-601. Lambeck, R.J. 1997. Focal species: a multi-species umbrella for nature conservation. Conservation Biology 11: 849-856.

Landres, P.B., J. Verner and J.W. Thomas. 1988. Ecological uses of vertebrate indicator species: a critique. Conservation Biology 2: 316-328.

Lindenmayer, D.B., C.R. Margules, and D.B. Botkin. 2000. Indicators of biodiversity for ecologically sustainable forest management. Conservation Biology 14: 941-950.

McGarigal, K. and S. Cushman. 2002. Comparative evaluation of experimental approaches to the study of habitat fragmentation effects. Ecological Applications 12: 335-345.

McLaren, M.A., I.D. Thompson and J.A. Baker. 1998. Selection of vertebrate wildlife indicators for monitoring sustainable forest management in Ontario. The Forestry Chronicle 74: 241-248. 
Meidinger, D. and J. Pojar (eds.) 1991. Ecosystems of British Columbia. British Columbia Ministry of Forests, Victoria, British Columbia.

Messier, C. and D.D. Kneeshaw. 1999. Thinking and acting differently for sustainable management of the boreal forest. The Forestry Chronicle 75: 929-938.

Nelson, J. and R. Wells. 2000. The effect of patch size on timber supply and landscape structure. In R.G. D'Eon, J. Johnson and E.A. Ferguson (eds.). Ecosystem management of forested landscapes: directions and implementation. pp. 195-207. University of British Columbia Bookstore, Vancouver, British Columbia.

Pojar, J., D. Klinka and D.V. Meidinger. 1987. Biogeoclimatic ecosystem classification in British Columbia. Forest Ecology and Management 22: 119-154.

Province of British Columbia. 1993. A protected areas strategy for British Columbia. Government of British Columbia, Victoria, British Columbia.

Riverside. 2003. Tree farm licence 49 ecological stewardship plan second approximation. Riverside Forest Products, Kelowna, British Columbia.

Seymour, R.S. and M.L. Hunter, Jr. 1999. Principles of ecological forestry. In M.L. Hunter Jr. (ed.). Maintaining Biodiversity in Forest Ecosystems. pp. 22-61. Cambridge University Press, Cambridge. Serrouya, R. and J. Herbers. 2002. Ecological representation: habitat attributes in constrained landbases in Riverside's TFL 49. Unpublished report submitted to Riverside Forest Products, Kelowna, British Columbia.
Serrouya, R., J. Herbers and K. Maxcy. 2002. Ecological representation analysis in Riverside TFL 49. Unpublished report submitted to Riverside Forest Products, Kelowna, British Columbia.

Simberloff, D. 1998. Flagships, umbrellas, and keystones: is singlespecies management passé in the landscape era? Biological Conservation 83: 246-257.

Soulé, M.E. and M.A. Sanjayan. 1998. Conservation targets: do they help? Science 279: 2060-206.

Thomas, J.W. 1979. Wildlife in managed forests. USDA Forest Service Agricultural Handbook No. 533, Washington, DC.

United Nations. 1992. Convention on biological diversity. New York, New York.

Walters, C. 1986. Adaptive management of renewable resources. MacMillian Publishing Company, New York, New York.

Watson, J., D. Freudenberger and D. Paull. 2001. An assessment of the focal-species approach for conserving birds in variegated landscapes in southeastern Australia. Conservation Biology 15 1364-1373.

Wells, R.W., F.L. Bunnell, D. Haag and G. Sutherland. 2003. Evaluating ecological representation within differing planning objectives for the central coast of British Columbia. Canadian Journal of Forest Research 33: 2141-2150. 